\section{PR-Set7-dependent methylation of histone H4 Lys 20 functions in repression of gene expression and is essential for mitosis}

\author{
Dmitry Karachentsev, ${ }^{1}$ Kavitha Sarma, ${ }^{2}$ \\ Danny Reinberg, ${ }^{2}$ and Ruth Steward ${ }^{1,3}$ \\ ${ }^{1}$ Waksman Institute, Department of Molecular Biology and \\ Biochemistry, New Jersey Cancer Center, Rutgers University, \\ Piscataway, New Jersey 08854-8020, USA; ${ }^{2}$ Howard Hughes \\ Medical Institute Division of Nucleic Acid Enzymology, \\ Department of Biochemistry, University of Medicine and \\ Dentistry of New Jersey, Robert Wood Johnson Medical \\ School, Piscataway, New Jersey 08854, USA
}

The histone methyl transferase PR-Set7 mediates histone $\mathrm{H} 4$ Lys 20 methylation, a mark of constitutive and facultative heterochromatin. We isolated a null mutation in Drosophila PR-Set7 that suppresses position effect variegation, indicating that PR-Set7 indeed functions in silencing general gene expression. In PR-Set7 larval leg and eye discs, the number of cells is lower than normal, and the DNA content in these cells is significantly increased. These data show that PR-Set7-dependent methylation is essential for the process of mitosis. The methylation mark is highly stable and is maintained even in the absence of PR-Set7 protein.

Supplemental material is available at http://www.genesdev.org.

Received September 16, 2004; revised version accepted December 27, 2004.

The development of a single cell into an embryo consisting of specific tissues is dependent on cascades of cellto-cell signaling events that activate transcription factors controlling the expression of specific genes. Control of expression of these genes can be regulated at two levels: the interplay of transcription factors that bind DNA directly, and the conformation of chromatin that controls the access of the transcription factors to the DNA. Recently it has become clear that chromatin organization is regulated in part by post-translational modification of the four histone proteins that control the packaging of DNA into the nucleosome, the basic unit of chromatin.

The nucleosome consists of an octamer of two copies of the four core histones $\mathrm{H} 2 \mathrm{~A}, \mathrm{H} 2 \mathrm{~B}, \mathrm{H} 3$, and $\mathrm{H} 4$, around which 146 base pairs of DNA are wound (Luger et al. 1997). The N-terminal tails of the four core histones are exposed on the nucleosome surface and are targets for a

[Keywords: Histone methylation; facultative and constitutive heterochromatin; transcriptional repression; cell cycle and mitosis; Drosophila] ${ }^{3}$ Corresponding author.

E-MAIL steward@waksman.rutgers.edu; FAX (732) 445-5735.

Article published online ahead of print. Article and publication date are at http://www.genesdev.org/cgi/doi/10.1101/gad.1263005. variety of enzyme-catalyzed, post-translational modifications of selected amino acids. These modifications include lysine acetylation, serine phosphorylation, ubiquitination, poly ADP-ribosylation, and lysine and arginine methylation (Stahl and Allis 2000; Zhang and Reinberg 2001). Particular histone modifications can control different states of chromatin. A particularly exciting possibility is that these modifications may transmit epigenetic information from one cell generation to the next. Histone lysine methylation is a relatively stable modification that correlates with transcriptional activation (H3-K4, H3-K36, H3-K79) or with transcriptionally repressed chromatin (H3-K9, H3-K27, H4-K20) depending on the residues that are modified (van Holde 1988; Strahl et al. 1999; Rice and Allis 2001; Zhang and Reinberg 2001).

Monomethylation of Lys 20 of histone $\mathrm{H} 4$ is regulated by the methyl transferase PR-Set7 (Nishioka et al. 2002; B. Xiao, C. Jing, G. Kelly, P.A. Walker, F.W. Muskett, T.A. Frenkiel, K. Sarma, D. Reinberg, S.J. Gamblin, and J.R. Wilson, in prep.), or Set8 (Fang et al. 2002), while trimethylation of the same amino acid occurs through the action of Suv4-20 (Schotta et al. 2004). Both enzymes contain an evolutionarily conserved SET domain (Jenuwein et al. 1998). The PR-Set7-mediated methylation of $\mathrm{H} 4-\mathrm{K} 20$ correlates with repression, as it is found in association with facultative and constitutive heterochromatin. Moreover, methylation of H4-K20 interferes with H4-K16 acetylation, a mark associated with active chromatin (Nishioka et al. 2002). In HeLa cells, the expression of PR-Set7 was found to be cell cycle-regulated, with a steep increase in late G2 and early mitosis. Further, in HeLa cells, PR-Set7 was observed specifically on mitotic chromosomes (Rice et al. 2002).

The Drosophila PR-Set7 ortholog is predicted to be a $76-\mathrm{kDa}$ protein (CG3307) with a SET domain that is $\sim 40 \%$ identical to the human domain. In the Drosophila gene disruption project, a single P-insertion into the 5'UTR of the gene was isolated. This partial loss-of-function allele, 1(3)neo41, is hemizygous lethal at the late pupal stage. We have isolated a complete loss-of-function PR-Set 7 allele in order to determine the functional importance of the gene. In the homozygous null mutants, the maternally deposited PR-Set7 protein does not perdure into the first instar larval stage, but mono-, di-, and trimethylation of $\mathrm{H} 4-\mathrm{K} 20$ are still present at late larval stages, when all three methyl marks disappear.

PR-Set 7 mutants suppress variegation, confirming that PR-Set7 functions in silencing gene expression. $P R$ Set7 mutants die at the larval-to-pupal transition and show strong phenotypes in their imaginal discs; the number of cells in the discs is reduced and the content of DNA increased, suggesting a failure to complete cell division. The reduced eye phenotype seen in rare mutant escapers confirms the importance of $P R$-Set 7 function in mitosis.

\section{Results and Discussion}

\section{A PR-Set7 complete loss of function allele}

The existing 1(3)neo41 mutation is caused by a P-element insertion into the 5'UTR of the PR-Set7 gene and is lethal at the late pupal stage over $D f(3 R)$ red31 (Fang et 

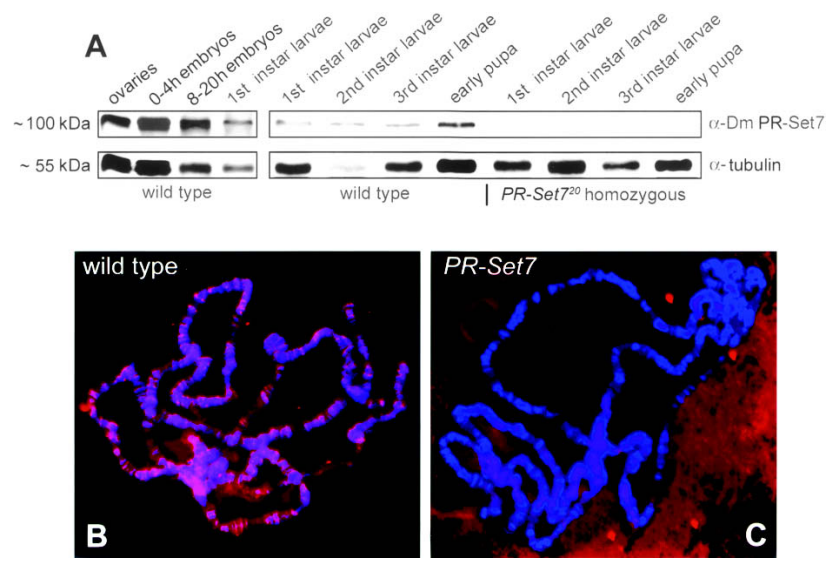

Figure 1. $P R-\operatorname{Set} 7^{20}$ mutants lack the PR-Set7 methylase. $(A)$ Western blot of protein extracts derived from wild-type and homozygous $P R-S_{\text {Set }} 7^{20}$ tissue, probed with anti-Drosophila PR-Set7 antibodies. $(B, C)$ Immunofluorescent staining of wild-type $(B)$ and $P R-\operatorname{Set}^{20}(C)$ salivary gland chromosomes with anti-Drosophila PR-Set7 antibodies (red) and Hoechst DNA dye (blue).

al. 2002; Nishioka et al. 2002; see also Materials and Methods). Such insertions frequently result in partial loss of function of the gene (Spradling 1986). In order to obtain a complete loss of function allele, we took advantage of a new P-element insertion obtained from the Drosophila stock center, PR-Set $7^{E Y 04668}$. This allele is lethal in homozygous pupae. By mobilizing this P-element we isolated a deletion in which the entire PR-Set7 protein coding region is missing $\left(P R-S_{e t}{ }^{20}\right)($ Supplementary Fig. S1). PR-Set $7^{20}$ homozygotes or hemizygotes over $D f(3 R)$ red31 show a somewhat stronger phenotype: Most animals die at the larval-to-pupal transition, with rare escapers surviving into early pupal stage. We determined the presence and perdurance of PR-Set7 protein in wild-type and mutant animals using anti-Drosophila PRSet7 antibody raised in Rats against Drosophila recombinant PR-Set7 (Materials and Methods).

In Western blots (Fig. 1A), a band of $\sim 100 \mathrm{kDa}$ is present in extracts of wild-type ovaries, early embryos, and throughout development, suggesting that PR-Set7 is deposited in the egg during oogenesis. In extracts form homozygous PR-Set7 animals, the $\sim 100-\mathrm{kDa}$ band is missing, while $\alpha$-tubulin is clearly present. These results show that the antibody recognizes the PR-Set7 protein specifically. They further show that the maternally deposited PR-Set7 protein does not perdure into first instar larvae, since the band is missing in homozygous mutants.

Using the antibody to stain salivary gland chromosomes, we found that the PR-Set7 protein is associated with the chromocenter and with the chromosome arms, mostly with densely packed DNA (Fig. 1B), indicating that PR-Set7 is associated with facultative and constitutive heterochromatin as well as with euchromatin. The chromosomal staining appears specific for PR-Set7, as no staining is observed on $P R$-Set $7^{2 O}$ salivary gland chromosomes (Fig. 1C).

These results show that even though the protein is missing in the mutants from first instar larval stage onward, the homozygous mutant $P R-S e t 7^{2 O}$ animals can survive until late larval to early pupal stages.

\section{PR-Set7 functions as a silencer}

Based on the localization of methylated H4-K20 on salivary gland chromosomes at transcriptionally inactive regions, we proposed that this methylation functions to nucleate higher-order structures that would maintain chromatin in an inactive state (see Nishioka et al. 2002). To determine whether indeed PR-Set 7 functions as a silencer, we examined its capability to suppress variegation. When euchromatic genes such as the wild-type white $\left(w^{+}\right)$gene in Drosophila are inserted into heterochromatic regions, the condensed chromatin structure of heterochromatin often spreads into the euchromatic region, resulting in full or partial inactivation of the genes (Cryderman et al. 1998, 1999). This results in variegated expression of the genes, easily seen in Drosophila eyes (position effect variegation, PEV).

To measure the level of expression of the $w^{+}$gene we measured the amount of red pigment in extracts of fly heads and found that both $D f(3 R)$ red 31 and the $P R$ Set $7^{2 O}$ allele function as dominant suppressors of PEV (Fig. 2A). The expression of $w^{+}$transgenes inserted into centromeric and telomeric heterochromatin of the fourth chromosome is significantly activated by the loss of function of one copy of PR-Set7 (Fig. 2A,B). PEV of $w^{+}$ insertions on chromosomes two and three were not

A

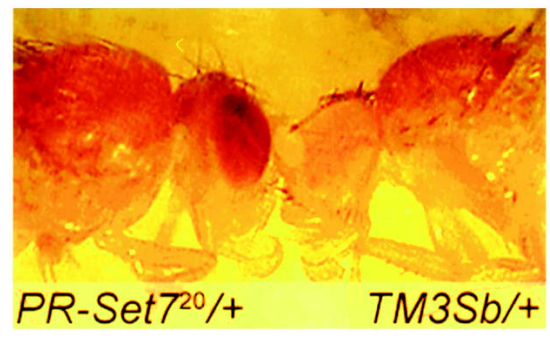

B

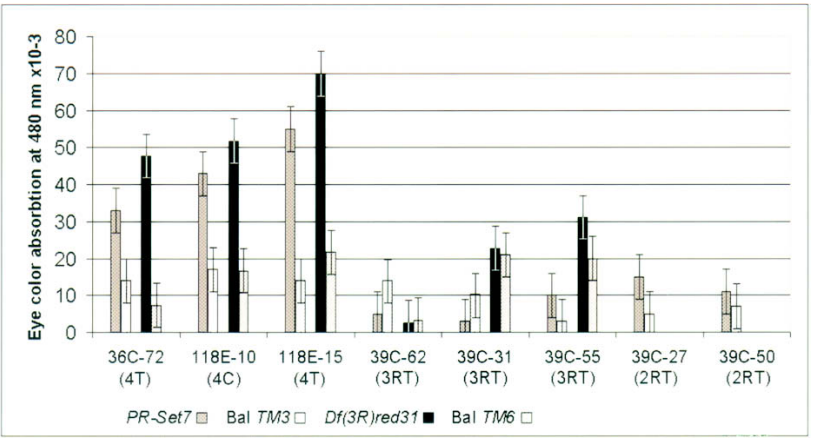

Figure 2. Reduction of PR-Set7 suppresses position effect variegation (PEV). (A,right) TM $3 S b /+$ fly showing variegated expression of a $W^{+}$transgene. (Left) $P R-S e t 7^{20} /+$ fly has red eyes because the variegated expression of the $W^{+}$transgene has been suppressed. $(B)$ Measurement of eye-color (OD $480 \mathrm{~nm}$ ) of extracts from different transgenic $w^{+}$lines expression, in heterozygous $P R$-Set7 flies $\left(P R-S e t 7^{20}\right)$ +, or $D f(3 R)$ red31/+), or wild-type flies $(B a l /+)$. Deletion of one copy of the $P R$-Set 7 gene increases the eye color significantly, confirming the suppression of variegation. The balancers used were TM3 and TM6. The transgenic lines used were 36C-72 and 118E-15 containing $\mathrm{W}^{+}$in the telomeric heterochromatin of the fourth chromosome. $118 \mathrm{E}-10$ contains a $w^{+}$transgene in the centromeric heterochromatin. All second and third $W^{+}$transgenic lines contain the transgene in the telomeric heterochromatin. 
changed (Fig. 2B). This result shows that indeed PR-Set7 functions as a repressor of gene activation and supports our previous supposition that was based only on distribution of the protein on chromosomes (Nishioka et al. 2002).

Mono-, di-, and trimethylation of histone H4-K2O is affected in PR-Set7 mutants

We investigated the mono-, di-, and trimethylated state of histone H4-K20 in wild-type and mutant larvae by antibody staining of salivary gland chromosomes and by Western blot. The staining of salivary gland chromosomes with the antibody specific for mono-, di-, or trimethylated histone H4-K20 shows that all three methyl marks have an indistinguishable distribution, with the exception of trimethyl H4-K20 appearing more abundant in centromeric heterochromatin (Fig. 3A,C,E; see also Schotta et al. 2004). This result agrees with studies demonstrating that trimethylation of H4-K20 is preferentially a pericentromeric mark (Schotta et al. 2004). On salivary gland chromosomes derived from homozygous PR-Set $7^{20}$ mutants, the level of all three forms of methylated H4-K20 was reduced (Fig. 3B,D,F). This reduction was only observed in late-stage larvae and was usually stronger on the chromosome arms than in the centromeric regions. The salivary chromosome preparations were costained with antibody recognizing the transcriptionally active form of RNA polymerase II. Both wildtype and mutant glands showed strong polymerase staining, indicating that the chromosomes are intact and that the reduced levels of the methylated forms of H4-K20 are not due to degradation of the chromosomes (Fig. 3A-F).

\section{Methylation of H4-K20 is essential for mitosis}

Homozygous PR-Set7 larvae generally die at the larvalto-pupal transition. Although the salivary glands and the chromosomes of such mutants look relatively normal, a distinct phenotype can be observed in tissues with higher rates of cell divisions such as larval imaginal discs (Fig. 4A). Imaginal discs are epithelial sacs made up of a folded, columnar epithelium on one side and a squamous epithelium on the other side (Bate and Arias 1993). The columnar discs cells are very small, only a few microns in size. The pictures shown in Figure 4A show the folded columnar epithelium of leg and eye discs from wild-type and $P R$-Set 7 late third instar larvae. The mutant discs are $10 \%-20 \%$ smaller than the wild-type discs and contain a significantly smaller number of cells. We counted the number of cells in optical sections prepared on a confocal microscope, and compared wild-type and mutant eye discs (Supplementary Fig. S2). The amount of DNA in each cell was determined by measuring the intensity of Hoechst fluorescence (Materials and Methods). We found that in wild-type discs there are approximately four times as many cells as in the mutant discs, and the fluorescence of nuclei indicates that there is $\sim 3.5$ times more DNA in mutant nuclei compared with wild-type (Supplementary Fig. S2). Further, hetero-allelic PR-Set7 mutants 1(3)neo41/PR-Set $7^{20}$ rarely survive to adulthood and die soon after eclosion. In these escapers the eye is reduced in size and irregular, consistent with the phenotype observed in the eye discs of homozygous $P R-S_{e t} 7^{2 O}$ larvae (Fig. 4B).

These results show that PR-Set7-controlled methylation of H4-K20 is essential for normal cell cycle progression. The mutant cells seem to undergo DNA replication but fail to complete mitosis.

\section{The monomethyl H4-K20 mark is highly stable}

Our analysis of PR-Set7 protein in wild-type animals reveals a protein on Western blots that appears to be significantly larger than the predicted size of $76 \mathrm{kDa}$. This difference in size could, at least in part, be due to as yet uncharacterized modifications of the enzyme. Several experiments show that our antibody specifically recognizes the Pr-Set7 protein. The protein is absent in extracts from mutant animals, and it is not detectable on mutant salivary gland chromosomes (Fig. 1A-C). Further, Flag-tagged PR-Set7 expressed in flies is recognized as a larger protein in Western blots of extracts from transgenic lines (data not shown).

The Western blots also show that mutant first instar larvae are devoid of the enzyme. Nevertheless, the homozygous mutant animals live until the late third instar larval stage. PR-Set7 is expressed in oogenesis and is deposited into the egg and is still detectable in early embryos, resulting in the synthesis of monomethyl H4-K20, present in oocytes and early embryos. Zygotic transcription of PR-Set7 presumably starts during embryogenesis, and PR-Set7 is present throughout development, as expected from a gene functioning in the cell cycle. The presence of monomethylated H4-K20 in the third instar
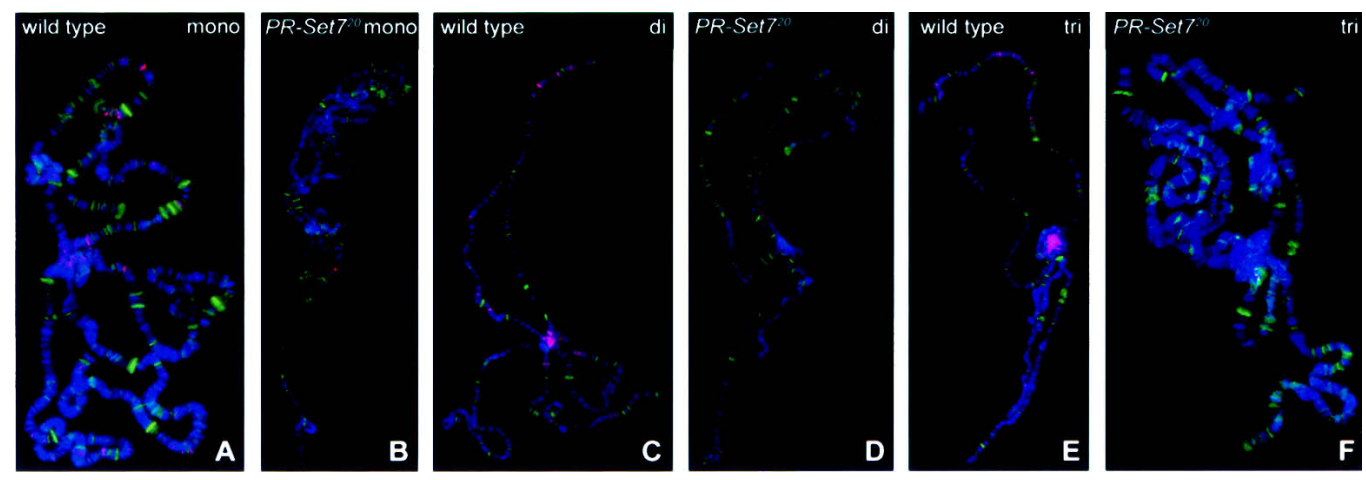

Figure 3. The mono-, di-, and trimethylation mark of H4-K20 is reduced in PR-Set7 mutants. Immunofluorescent staining of wild-type $(A, C, E)$ and $P R-\operatorname{Set}^{20}(B, D, F)$ salivary gland chromosomes with anti-monomethylated $(A, B)$, anti-dimethylated $(C, D)$, and anti-trimethylated $(E, F)$ H4-K20 antibodies (red) and antibody recognizing the catalytic subunit of RNA polymerase II (green). DNA dye Hoechst (blue). 
Karachentsev et al.

PR-Set7 mutant larvae indicates that this methylation mark of histone H4-K20 is stable over several days and several cell generations, or that an additional methylase exists that controls the methylation of $\mathrm{H} 4-\mathrm{K} 20$ up to late larval stages.

These results agree well with observations previously obtained in HeLa cells (Rice et al. 2002). In these cells $P R-S e t 7$ expression is controlled transcriptionally and fluctuates with different stages of the cell cycle. Both mRNA and protein levels are lowest in G1 and highest during G2/M. In parallel, methylation levels of H4-K20 also cycle but the cycling is not pronounced, suggesting that the methylation is stable over more than one cell generation.

Our results suggest that monomethylation is a prerequisite for di- and trimethylation to occur or be stabilized. At least two scenarios can explain this result: (1) Suv4-20 and a possible dimethylase may modify primarily a monomethylated H4-K20 substrate. (2) The arrest in the cell cycle in the $P R-S e t 7$ mutant could result in reduced levels of the di- and trimethylated forms of H4-K20.

Only a partial loss-of-function allele of the newly identified Suv4-20 gene exists (Schotta et al. 2004). Further work will be necessary to fully understand the connection between mono-, di-, and trimethylation.

\section{Methylated histone H4-K20 functions as a repressor}

Our results indicate that PR-Set7 functions as a suppressor of gene expression and hence as a SUVAR. This ob-

\section{A}

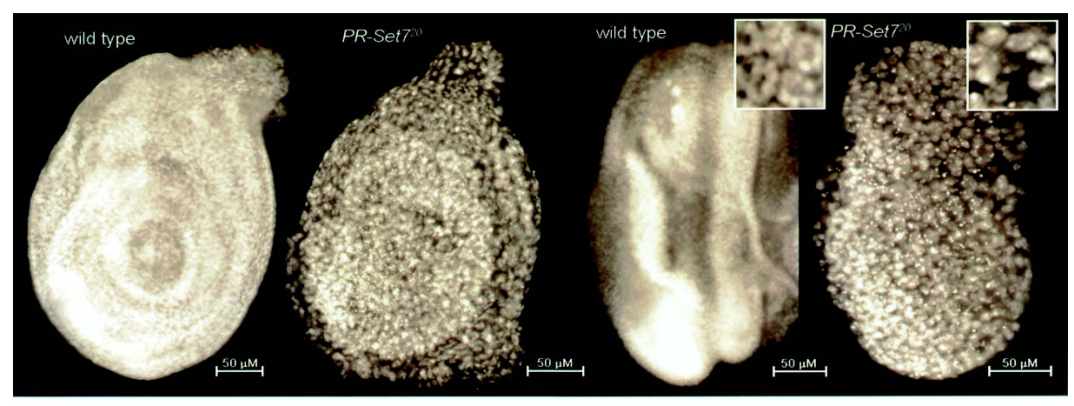

B

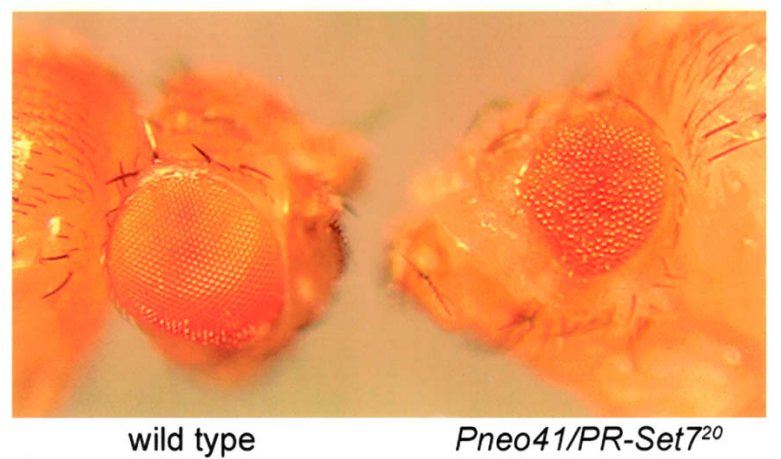

Figure 4. In $P R-S e t 7^{20}$ animals, the mitotic process is interrupted. $(A)$ Leg imaginal discs (left) and eye imaginal discs (right) of wild-type and PR-Set7 larvae stained with the DNA dye Hoechst (white). (B) Eyes of wild-type and PR-Set7 partial loss-of-function flies. Note the smaller eye size in irregular organization of the mutant eye. servation is consistent with our previous finding that monomethylated H4-K20 is strongly associated with silent chromatin of polytene chromosomes. It is not clear why the suppression is only observed with $w^{+}$transgenes inserted on the fourth chromosome. Since in this genetic interaction experiment the amount of Pr-Set7 function is reduced by only $50 \%$, it is possible that a stronger reduction of the enzyme would also affect the expression of $\mathrm{W}^{+}$ transgenes inserted into the heterochromatin of other chromosomes. Our results suggest that the heterochromatin organization on the fourth chromosome differs from that of the other autosomes (Schotta et al. 2002).

It is likely that monomethylated $\mathrm{H} 4-\mathrm{K} 20$ regulates the packaging of silent chromatin domains in constitutive and facultative heterochromatin. Because PR-Set7 mutants show a cell-cycle defect phenotype, we propose that the monomethylated $\mathrm{H} 4-\mathrm{K} 20$ is associated with regions containing cell-cycle genes that must remain repressed in early mitosis. Alternatively, the chromosomal regions associated with monomethylated H4-K20 may represent a flag for a cell-cycle checkpoint control or be otherwise involved in separation of chromosomes.

\section{PR-Set7 is essential for mitosis}

The cell cycle-regulated expression of PR-Set7 (Rice et al. 2002) is consistent with the observed phenotype of PR-Set 7 mutants that go through $S$ phase normally but enter into an endoreplication cycle. This phenotype is most easily seen in diploid tissues such as imaginal discs.

Imaginal disc cells undergo $\sim 12$ divisions from the end of embryogenesis to the late third instar larval stage (Bate and Arias 1993). Because PR-Set7 discs have about four times fewer cells and 3.5 times more DNA, mitosis probably is affected about two cell divisions before the final development of the discs, in mid-third instar larvae. This is about the same time when the H4-K20 methyl mark begins to disappear.

Investigating the function of PR-Set7 using a short interfering RNA (siRNA) approach in HeLa cells, Julien and Herr (2004) found no change in mitosis. In our experiments the mitosis phenotype is apparent in mutant larvae only $\sim 10$ cell divisions after the PR-Set7 enzyme is not detectable. The discrepancy in these results may lie in the fact that the timeframe of tissue culture experiments does not allow the detection of the mitosis phenotype. However, Julien and Herr (2004) also found that cells treated with HCF-1 and PR-Set7 siRNA have a weaker multinucleate phenotype than when HCF-1 siRNA is applied alone. They proposed that reduction in PR-Set7 and resulting changes in H4-K20 methylation have a function in mitosis. Based on our results we suggest that the effect of lowering PR-Set7 levels may arrest mitosis, resulting in fewer multinucleated cells than in cells treated with $H C F-1$ siRNA alone. The PR-Set7 phenotype may be more easily discernible in the sensitized background, when HCF-1 is reduced. 
In fission yeast, Schizosaccharomyces pombe, the Suv9 gene has been shown to be responsible for methylation of histone H4-K20. No role for the gene in control of gene expression could be demonstrated; rather, lack of $\mathrm{H} 4-\mathrm{K} 20$ methylation results in a defect in double-strand break repair and does not seem to affect mitosis (Sanders et al. 2004). It remains to be seen whether mono-, di- or trimethylation of histone H4-K20 functions in doublestrand break repair in Drosophila.

\section{Materials and methods}

Isolation of PR-Set7 complete loss of function allele

The existing 1(3)neo41 stock is homozygous lethal at the second instar, but only lethal at the late pupal stage over $D f(3 R)$ red31, presumably because of the existence of an unknown lethal mutation on the 1(3)neo4 chromosome. Fly stock \#15761-PR-Set $7^{E Y 04668}$ was obtained from Bloomington Stock Center (Supplementary Fig. S1; Spradling 1986). To study PEV, fly stocks bearing $w^{+}$transgenes inserted into centromeric or telomeric heterochromatin on the second, third, or fourth chromosome (Cryderman et al. 1998, 1999) were crossed with PR-Set720/TM3Sb or $D f(3 R)$ red31/TM6Tb. The eye color of F1 animals, bearing a transgene and also heterozygous for the PR-Set7 mutation, the deficiency, or a balancer chromosome was determined reading the OD 480 of an extract of 10 fly heads (Ashburner 1989).

\section{Antibodies and Western blots}

Recombinant his-tagged Drosophila PR-Set7 was expressed in Escherichia coli, purified under native conditions according to the manufacturer's protocol (QIAGEN), and used for raising polyclonal antibodies in rats. The specificity of the antibodies was checked by Western blots and the staining of wild-type and $P R-S e t 7^{20}$ tissues. Western blot analysis was performed as described (Whalen and Steward 1993). Antibodies were used in the following dilutions: $\alpha$-Dm-PR-Set7 rat polyclonal 1:500; $\alpha-\mathrm{H} 4-\mathrm{K} 20$ mono-, di-, and trimethyl, all rabbit polyclonal obtained from Upstate, 1:1000.

Salivary gland chromosome preparations and antibody staining Salivary glands of third instar larvae were dissected, and polytene chromosomes were isolated and mounted on slides as described (Lis et al. 2000). Polytene chromosomes were stained with 1:100 dilution of mouse monoclonal $\alpha$-Pol II antibody (Covance H5), $\alpha$-Dm-PR-Set7 rat polyclonal 1:100, $\alpha$-H4-K20 mono- and dimethyl rabbit polyclonal 1:100, $\alpha-\mathrm{H} 4-\mathrm{K} 20$ trimethyl rabbit polyclonal (Abcam) 1:100.

Antibody staining of tissues

Antibody staining of Drosophila ovaries and embryos was performed as described (Whalen and Steward 1993). The CNS of third instar larvae were dissected, and mitotic chromosomes prepared as described (Ashburner 1989). Staining was visualized using a Zeiss Axioplan 2 microscope and an AxioCam HRm digital camera.

Imaginal discs of third instar larvae were stained with Hoechst. Measurements of fluorescence were done on a Zeiss Axioplan 2 microscope and AxioCam HRm digital camera. Pictures were analyzed with the Image Pro Plus imaging software. The relative units represent the intensity of fluorescence present in a defined field under identical exposures (Supplementary Fig. S2).

\section{Acknowledgments}

We thank Girish Deshpande and Andrew Vershon for helpful suggestions on the manuscript, and Greg Shanower for sending flies. We also thank Marina Druzhinina, Sirisha Pedapudi, and Le Nguyen for technical help and fly food. This work was supported by a grant from the NIH and by the W. Horace Goldsmith Foundation.

\section{References}

Ashburner, M. 1989. Drosophila-A laboratory handbook. Cold Spring Harbor Laboratory Press, Cold Spring Harbor, NY.

Bate, M. and Arias, A.M. 1993. The development of Drosophila melano- gaster, pp. 149-301. Cold Spring Harbor Laboratory Press, Cold Spring Harbor, NY.

Cryderman, D.E., Cuaycong, M.H., Elgin, S.C., and Wallrath, L.L. 1998. Characterization of sequences associated with position-effect variegation at pericentric sites in Drosophila heterochromatin. Chromosoma 107: 277-285.

Cryderman, D.E., Morris, E.J., Biessmann, H., Elgin, S.C., and Wallrath, L.L. 1999. Silencing at Drosophila telomeres: Nuclear organization and chromatin structure play critical roles. EMBO J. 18: 3724-3735.

Fang, J., Feng, Q., Ketel, C.S., Wang, H., Cao, R., Xia, L., ErdjumentBromage, H., Tempst, P., Simon, J.A., and Zhang, Y. 2002. Purification and functional characterization of SET8, a nucleosomal histone H4-lysine 20-specific methyltransferase. Curr. Biol. 9: 1086-1099.

Jenuwein, T., Laible, G., Dorn, R., and Reuter, G. 1998. SET domain proteins modulate chromatin domains in eu- and heterochromatin. Cell Mol. Life Sci. 54: 80-93.

Julien, E. and Herr, W. 2004. A switch in mitotic Histone H4 lysine 20 methylation status is linked to M phase defects upon loss of HCF-1. Mol. Cell 18: 713-725.

Lis, J.T., Mason, P., Peng, J., Price, D.H., and Werner, J. 2000. P-TEF $\beta$ kinase recruitment and function at heat shock loci. Genes \& Dev. 1: 792-803.

Luger, K., Mader, A.W., Richmond, R.K., Sargent, D.F., and Richmond, T.J. 1997. Crystal structure of the nucleosome core particle at $2.8 \mathrm{~A}$ resolution. Nature 18: 251-260.

Nishioka, K., Rice, J.C., Sarma, K., Erdjument-Bromage, H., Werner, J., Wang, Y., Chuikov, S., Valenzuela, P., Tempst, P., Steward, R., et al. 2002. PR-Set7 is a nucleosome-specific methyltransferase that modifies lysine 20 of histone $\mathrm{H} 4$ and is associated with silent chromatin. Mol. Cell. 9: 1201-1213.

Rice, J.C. and Allis, C.D. 2001. Code of silence. Nature 15: 258-261.

Rice, J.C., Nishioka, K., Sarma, K., Steward, R., Reinberg, D., and Allis, C.D. 2002. Mitotic-specific methylation of histone H4 Lys 20 follows increased PR-Set 7 expression and its localization to mitotic chromosomes. Genes \& Dev. 1: 2225-2230.

Sanders, S.L., Portoso, M., Mata, J., Bahler, J., Allshire, R.C., and Kouzarides, T. 2004. Methylation of histone H4 Lysine 20 controls recruitment of crb2 to sites of DNA damage. Cell 24: 603-614.

Schotta, G., Ebert, A., Krauss, V., Fischer, A., Hoffmann, J., Rea, S., Jenuwein, T., Dorn, R., and Reuter, G. 2002. Central role of Drosophila SU/VAR)3-9 in histone H3-K9 methylation and heterochromatic gene silencing. EMBO J. 21: 1121-1131.

Schotta, G., Lachner, M., Sarma, K., Ebert, A., Sengupta, R., Reuter, G., Reinberg, D., and Jenuwein, T. 2004. A silencing pathway to induce H3-K9 and H4-K20 trimethylation at constitutive heterochromatin. Genes \& Dev. 1: 1251-1262.

Spradling, A.C. 1986. P-element mediated transformation. In Drosophila: A practical approach (ed. D.B. Roberts), pp. 175-197. IRL Press, Oxford, UK.

Strahl, B.D. and Allis, C.D. 2000. The language of covalent histone modifications. Nature 403: 41-45.

Strahl, B.D., Ohba, R., Cook, R.G., and Allis, C.D. 1999. Methylation of histone $\mathrm{H} 3$ at lysine 4 is highly conserved and correlates with transcriptionally active nuclei in Tetrahymena. Proc. Natl. Acad. Sci. 21: 14967-14972.

van Holde, K.E. 1988. Chromatin. In Molecular biology (ed. A. Rich), pp. 111-148. Springer, New York.

Whalen, A.M. and Steward, R. 1993. Dissociation of the dorsal-cactus complex and phosphorylation of the dorsal protein correlate with the nuclear localization of dorsal. J. Cell Biol. 123: 523-534.

Zhang, Y. and Reinberg, D. 2001. Transcription regulation by histone methylation: Interplay between different covalent modifications of the core histone tails. Genes \& Dev. 15: 2343-2360. 


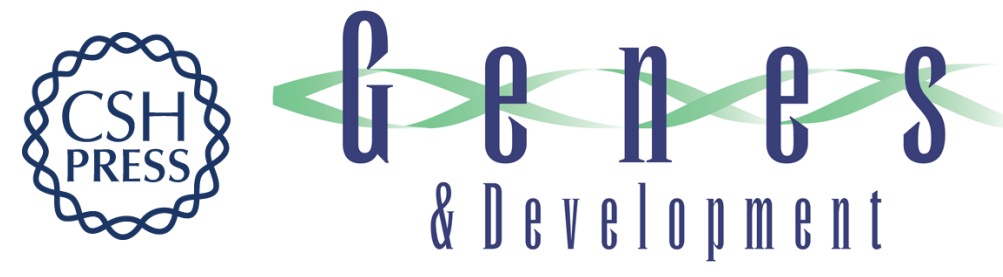

\section{PR-Set7-dependent methylation of histone H4 Lys 20 functions in repression of gene expression and is essential for mitosis}

Dmitry Karachentsev, Kavitha Sarma, Danny Reinberg, et al.

Genes Dev. 2005, 19:

Access the most recent version at doi:10.1101/gad.1263005

Supplemental http://genesdev.cshlp.org/content/suppl/2005/01/25/gad.1263005.DC1
Material

References This article cites 12 articles, 4 of which can be accessed free at: http://genesdev.cshlp.org/content/19/4/431.full.html\#ref-list-1

License

Email Alerting Receive free email alerts when new articles cite this article - sign up in the box at the top Service right corner of the article or click here.

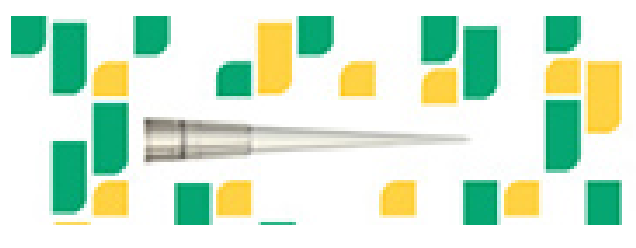

Focused on your science. 